|| Print ISSN: 2589-7837 || Online ISSN: 2581-3935 ||

International Journal of Medical Science and Diagnosis Research (IJMSDR)

Available Online at www.ijmsdr.com

NLM (National Library of Medicine ID: 101738824)

Original Research Article

Volume 5, Issue 10; October:2021; Page No. 28-33

\title{
Role of Lipid Profile and Fasting Blood Glucose in Metabolic Syndrome
}

\author{
Pavan Gautam ${ }^{1}$, Shreya Nigoskar ${ }^{2}$, Bibek Bhurer Yadav ${ }^{3}$ \\ ${ }^{1} \mathrm{PhD}$ Scholar, IMCHRC, Indore, MP \\ ${ }^{2}$ Department of Biochemistry, IMCHRC, Indore, MP \\ ${ }^{3}$ SGT Medical College, Haryana
}

\section{Conflicts of Interest: Nil}

Corresponding author: Pavan Gautam

DOI: https://doi.org/10.32553/ijmsdr.v5i10.865

\begin{abstract}
:
Background: The metabolic syndrome is defined by the clustering of risk factors that predisposes people to diabetes and cardiovascular disease (CVD. MetS had a high (58\%) prevalence of dyslipidemia, and increasing age, greater BMI, central obesity, hypertension, and high blood glucose levels have been found as independent predictors of dyslipidemia.

Aim of the Work: This study aimed to role of lipid profile and fasting blood glucose in metabolic syndrome.

Subjects and Methods: The research was carried out at the Index Medical College and Research Center in Indore, in the Department of Biochemistry. A total of 120 people with metabolic syndrome and 120 healthy controls were included in the study. A blood sample was taken from the anticubital vein and centrifuged to obtain serum, which was then evaluated for lipid profile and FBS levels quantitatively. Result and Conclusion: Present study suggested that the FBG is the most critical factor in MS, and all aspects of the lipid profile have significant relationships with MS.
\end{abstract}

Keywords: Metabolic syndrome, fasting blood glucose

\section{Introduction:}

The metabolic syndrome is defined by the clustering of risk factors that predisposes people to diabetes and cardiovascular disease (CVD) ${ }^{1,2}$. Glucose intolerance, obesity, high blood pressure, and dyslipidemia are the key features of the syndrome. As a significant modifiable factor of cardiovascular disease and type- 2 diabetes, it is increasingly garnering the attention of international research organizations and scientific organisations $^{3-5}$.

The plurimetabolic syndrome, the $\mathrm{X}$ syndrome, the $\mathrm{X}$ plus syndrome, the $\mathrm{X}$ metabolic syndrome, the cardiovascular metabolic syndrome, the insulinresistance - dyslipidemia syndrome, the atherogenic metabolic syndrome, the syndrome of atherogenic factors agglomeration, and the deadly quartet have all been given to the metabolic syndrome over time. The MetS abbreviation has recently been used to replace the term Metabolic Syndrome. The World Health Organization (WHO), the International Diabetes Federation (IDF), and other international agencies agreed on the term "metabolic syndrome" as the best way to describe this nosologic entity.

Because of the many points of view on the variables required for the diagnosis, estimating the metabolic syndrome is complicated. It's not about a single disease, but rather a cluster of symptoms 
that can arise suddenly or gradually in the same person, as a result of combining hereditary and environmental factors (lifestyle) with insulin resistance, which is regarded the primary pathogenic component.

Alternative clinical criteria for identifying Metabolic Syndrome were developed in 2001 by NCEP ATP III (National Cholesterol Education Programme, Adult Treatment Panel III). The presence of insulin resistance is not required by the ATP III criterion ${ }^{6}$.

According to the modified NCEP ATP III definition of the metabolic syndrome, at least three of the following parameters are present ${ }^{7}$ :

- Waist circumference $\geq 90 \mathrm{~cm}$ for Asian men

$\geq 80 \mathrm{~cm}$ for Asian women

- Fasting triglycerides $\geq 150 \mathrm{mg} / \mathrm{dl}(\geq 1.7 \mathrm{mmol} / \mathrm{l})$ or drug treatment for elevated triglycerides

- HDL cholesterol $<40 \mathrm{mg} / \mathrm{dl}(1.03 \mathrm{mmol} / \mathrm{l})$ in men

$<50 \mathrm{mg} / \mathrm{dl}(1.30 \mathrm{mmol} / \mathrm{l})$ in women

or drug treatment for reduced HDL cholesterol

- Blood pressure $\geq 130 / 85 \mathrm{mmHg}$ or drug treatment for elevated blood pressure

- Fasting glucose $\geq 100 \mathrm{mg} / \mathrm{dl}(\geq 5.6 \mathrm{mmol} / \mathrm{l})$ or drug treatment for elevated glucose

The MetS, which includes central obesity, hypertension, dyslipidemia (high $\mathrm{Tg}$ and low HDL) and glucose intolerance, is now a wellknown entity in which each component of the syndrome increases CVD risk and is more powerful when combined. MetS symptoms might be present for up to ten years before glycemic problems are discovered ${ }^{8}$.

The MetS is characterized by an increase in plasma Tgs and a decrease in HDL-C. Although high LDL-C is not a defining feature, a rise in the fraction of tiny dense LDL particles is frequently observed ${ }^{9}$.

One of the characteristics of MetS is an HDL-C concentration of less than $40 \mathrm{mg} / \mathrm{dL}$ in males and more than $50 \mathrm{mg} / \mathrm{dL}$ in females. Each of the other
MetS characteristics, such as increased $\mathrm{Tg}$, hypertension, and IR, is linked to a reduction in HDL. HDL in MetS patients is smaller and denser than usual, especially in those with Tg levels greater than $150 \mathrm{mg} / \mathrm{dL}^{10}$.

Low HDL content in MetS is due to an increased rate of HDL catabolism, potentially as a result of particle triglyceride enrichment, which reflects increased activity of the enzyme Cholesterol Ester Transport Protein (CETP). CETP facilitates the transfer of cholesterol esters from HDL to Tg-rich lipoproteins in exchange for $\mathrm{Tg}$, resulting in HDLs that are cholesteryl ester-depleted and Tg-rich. Hepatic lipase hydrolysis of Tg-rich HDL reduces the volume of the particle core, resulting in a reduction in particle size and dissociation of the lipid free/lipid-poor apoA-I from the HDL surface $^{11,12}$.

Increased $\mathrm{Tg}$ concentrations are another dyslipidemic characteristic that is a component of the MetS. Increased hepatic synthesis of very low density lipoprotein (VLDL) particles and impaired intravascular catabolism and plasma clearance of VLDL and intestinally derived chylomicron particles are promoted by excess adiposity and IR. Higher hepatic Tg content, which is generated in part from enhanced FFA acid supply from adipose tissue and return of Tg-rich lipoprotein remnants to the liver, is a significant predictor of increased VLDL production in the MetS. Increased FFA flux from the periphery stimulates hepatic Tg synthesis, which promotes Tg-containing VLDL assembly and secretion, as well as apoB formation in the liver. Increased hepatic production of VLDL particles is directly promoted by IR and compensatory hyperinsulinemia ${ }^{13}$.

When the WHO published the working definition for MetS in 1999, poor glucose regulation or diabetes, as well as insulin resistance and any two of the other components, were listed as mandatory. Fasting plasma glucose was one of the five components of MetS when the NCEP ATP III recommendations were written in 2001. Upstream insulin signaling processes are interfered with by IR, resulting in acquired insulin signaling abnormalities. It causes defective GLUT4 
translocation to the cell membrane in skeletal muscle, resulting in insulin-stimulated glucose uptake resistance. Insulin-mediated reduction of hepatic glucose synthesis is resistant in the liver. Increased plasma free fatty acid levels cause decreased insulin production by -cells, which contributes to hyperglycemia ${ }^{124}$ through increased intracellular expression of uncoupling protein ${ }^{14}$.

This study aimed to role of lipid profile and fasting blood glucose in metabolic syndrome

\section{Material and Methods:}

The research was carried out at the Index Medical College and Research Center in Indore, in the Department of Biochemistry. A total of 120 people with metabolic syndrome and 120 healthy controls were included in the study. Prior to the collection of blood samples, a Performa containing a questionnaire was filled out as a baseline record (Performa contained). During the research, all ethical precautions were taken. A blood sample was taken from the anticubital vein and centrifuged to obtain serum, which was then evaluated for lipid profile and FBG levels quantitatively.

The ANOVA test was used to compare the mean (SD) lipid profile and FBG level of the test group (metabolic syndrome) to that of the control group. Significant was defined as a $p$ value of less than 0.05 .

\section{Results}

Table-1 Shows statistical analyzes projected that the cholesterol, triglycerides, LDL and HDL found to be significantly. This was observed that the average (mean $\pm \mathrm{SD}$ ) cholesterol, triglycerides, LDL and HDL concentration that was found in the control group was $190.56 \pm 13.10,148.88 \pm 7.75$, $70.61 \pm 2.74$ and $50.67 \pm 4.24$, in the MetS group, it was $256.14 \pm 14.34,230.51 \pm 7.52,134.46 \pm 2.61$ and $27.74 \pm 2.61$ and in the DM group, it was $271.88 \pm 14.44,246.35 \pm 10.90,137.01 \pm 3.43$ and $33.56 \pm 3.38$. The cholesterol, triglycerides and LDL level was found to be significantly higher and HDL significantly low in comparison to that in the healthy subjects (control group), with a $\mathrm{p}$ value of $<0.001$. DM Group showed higher concentration of cholesterol, triglycerides and LDL and low concentration of HDL as comparison to MetS group. However, one-way anova of variance indicated that these differences in mean cholesterol, triglycerides, LDL and HDL among three groups were highly significant $(\mathrm{p}<0.001)$.

Table 1: Comparison of cholesterol, triglycerides, LDL and HDL in control, metabolic syndrome and diabetes mellitus patients

\begin{tabular}{|l|l|l|l|l|}
\hline PARAMETER & CONTROL & MetS & DM & P-VALUE \\
\hline Choldl) & (MEAN \pm SD) & (MEAN \pm SD) & (MEAN \pm SD) & \\
\hline Triglycerides & $190.56 \pm 13.10$ & $256.14 \pm 14.34$ & $271.88 \pm 14.44$ & $<0.001$ \\
\hline LDL & $70.61 \pm 2.74$ & $134.46 \pm 3.38$ & $137.01 \pm 3.43$ & $<0.001$ \\
\hline HDL & $50.67 \pm 4.24$ & $27.74 \pm 2.61$ & $33.56 \pm 3.38$ & $<0.001$ \\
\hline
\end{tabular}




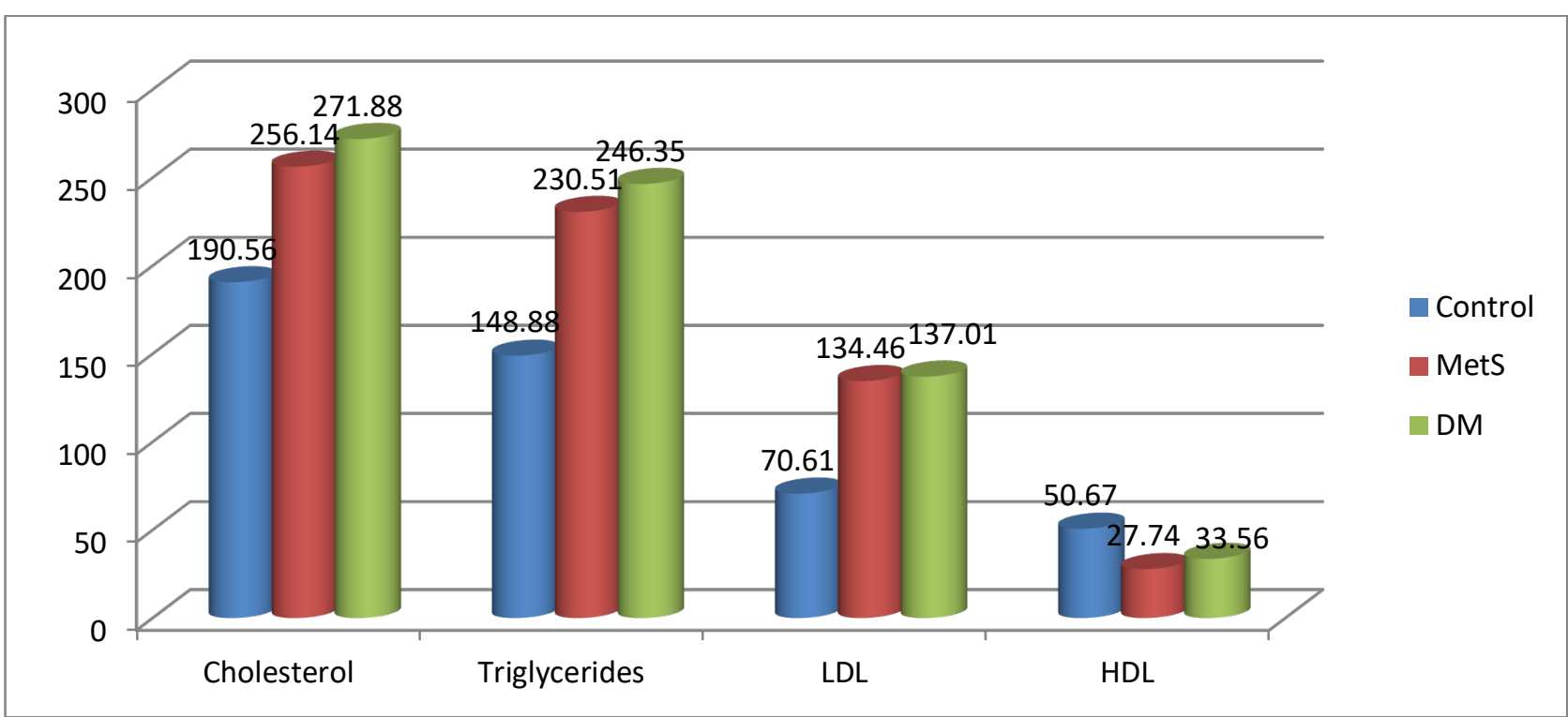

Figure 1: Comparison of cholesterol, triglycerides, LDL and HDL in control, metabolic syndrome and diabetes mellitus patients in the form of bar diagram.

Statistical analyzes projected that the FBS level was significantly increased in the DM \& MetS group when compared with control groups.

This was observed that the average (Mean $\pm \mathrm{SD}$ ) FBS concentration that was found in the control group was $101.62 \pm 2.96$, in the MetS group, it was $149.86 \pm 4.85$ and in the DM group, it was $166.77 \pm 5.17$. The FBS level was found significantly higher in comparison to that in the (healthy subjects) control group, with a $p$ value of $<0.001$. DM group showed higher level of FBS as comparison to MetS group. However, one-way anova of variance indicated that these differences in mean FBS among three groups were highly significant $(\mathrm{p}<0.001)$.

Table 2: Comparison of fasting blood glucose in control, metabolic syndrome and diabetes mellitus patients

\begin{tabular}{|l|l|l|l|l|}
\hline $\begin{array}{l}\text { PARAMETER } \\
(\mathbf{m g} / \mathbf{d l})\end{array}$ & $\begin{array}{l}\text { CONTROL } \\
(\text { MEAN } \pm \text { SD) }\end{array}$ & $\begin{array}{l}\text { MetS } \\
(\text { MEAN } \pm \text { SD) }\end{array}$ & $\begin{array}{l}\text { DM } \\
(\text { MEAN } \pm \text { SD) }\end{array}$ & P-VALUE \\
\hline FBS & $101.62 \pm 2.96$ & $149.86 \pm 4.85$ & $166.77 \pm 5.17$ & $<0.001$ \\
\hline
\end{tabular}

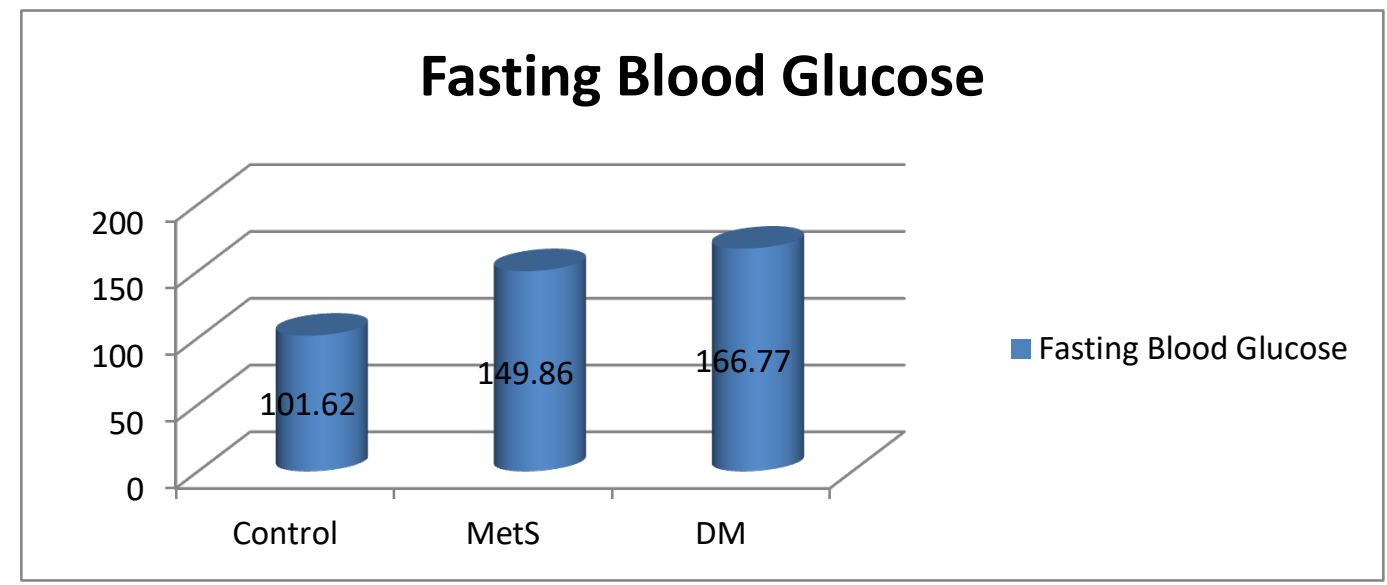

Figure 2: Comparison of fasting blood glucose in control, metabolic syndrome and diabetes mellitus patients in the form of bar diagram. 


\section{Discussion}

The cholesterol, triglycerides and LDL level was found to be significantly higher and HDL significantly low in comparison to that in the healthy subjects (control group). DM Group showed higher concentration of cholesterol, triglycerides and LDL and low concentration of HDL as comparison to MetS group.

The FBS level was found significantly higher in comparison to that in the (healthy subjects) control group, with a $\mathrm{p}$ value of $<0.001$. DM group showed higher level of FBS as comparison to MetS group.

These findings were concordant with the results of the studies, which were previously done by Haile et al., (2019) ${ }^{192}$ and Mohammadbeigi et al., (2018) ${ }^{193}$ found that the individuals with MetS had a high $(58 \%)$ prevalence of dyslipidemia, and increasing age, greater BMI, central obesity, hypertension, and high blood glucose levels have been found as independent predictors of dyslipidemia. Dyslipidemia prevention and control, as well as its predictors, were indicated for patients with MetS.

\section{Conclusion}

The cholesterol, triglycerides and LDL level was found to be significantly higher and HDL significantly low in comparison to that in the healthy subjects (control group). DM Group showed higher concentration of cholesterol, triglycerides and LDL and low concentration of HDL as comparison to MetS group. Fasting blood glucose levels in DM and MetS were significantly higher due to metabolic abnormalities such as central obesity, HTN, dyslipidemia, hyperglycemia, and insulin resistance, with central obesity and insulin resistance being identified as causal factors in particular. Present study suggested that the FBG is the most critical factor in MS, and all aspects of the lipid profile have significant relationships with MS.

\section{References}

1. Haffner SM, Valdez RA, Hazuda HP, Mitchell $\mathrm{BD}$, Morales PA. Prospective analysis of the insulin-resistance syndrome (syndrome $\mathrm{X}$ ). Diabetes 1992;41:715-22.

2. Isomaa B, Almgren P, Tuomi T, Forsén B, Lahti K. Cardiovascular morbidity and mortality associated with the metabolic syndrome. Diabetes Care 2001;24:683-89.

3. Cameron AJ, Shaw JE, Zimmet PZ. The metabolic syndrome: prevalence in worldwide populations. Endocrinol Metab Clin North Am. 2004;33:351-75.

4. Pekkanen J, Tuomilehto J, Uutela A, Vartiainen E, Nissinen A. Social class, health behaviour and mortality among men and women in eastern Finland. BMJ 1995;311:58993.

5. Davey Smith G, Neaton JD, Wentworth D, Stamler R, Stamler J. Mortality differences between black and white men in the USA: contribution of income and other risk factors among men screened for the MRFIT. MRFIT Research Group. Multiple Risk Factor Intervention Trial. Lancet 1998;351:934-39.

6. Brunner E.J. Social inequality in coronary risk: Central obesity and the metabolic syndrome. Diabetologia, 1997;40:1341-49.

7. Grundy SM, Cleeman JI, Daniels SR, Donato KA, Eckel RH. Diagnosis and management of the metabolic syndrome: an American Heart Association/National Heart, Lung and Blood Institute Scientific Statement. Circulation 2005;112:2735-52.

8. Shankar P, Sundarka M. Metabolic syndrome: Its pathogenesis and management. JIACM 2003;4(4):275-281.

9. Krauss RM, Siri PW. Metabolic abnormalities: triglyceride and lowdensity lipoprotein. Endocrinol Metab Clin N Am 2004;33:405415.

10. Barter P. Metabolic abnormalities: highdensity lipoproteins. Endocrinol Metab Clin N Am 2004;33:393-403.

11. Duvillard L, Pont F, Florentin E, Gambert B, Verges B. Inefficiency of insulin therapy to correct apolipoprotein A-I metabolic abnormalities in non-insulin-dependent diabetes mellitus. Atherosclerosis 2000; 152:229-237. 
12. Baldeweg SE, Golay A, Natali A, Balkau B, Del Prato S, Soppack SW. insulin resistance, lipid and fatty acid concentrations in 867 healthy Europeans: European group for the study of insulin resistance (EGIR). Eur J Clin Invest 2000;30:45-52.
13. Kolovou GD, Anagnostopoulou KK, Cokkinos DV. Pathophysiology of dyslipidemia in the metabolic syndrome. Postgrad Med J 2005; 8:358-366.

14. IDF diabetes atlas -5 th edition: The global burden. 